\title{
EXPERIMENTAL INVESTIGATION OF FLOATING FISH FARMS BEHAVIOUR IN WAVES
}

\author{
Rumen Kishev**, Silvia Kirilova and Olena Videnova \\ Institute of Metal Science, Equipment and Technologies \\ with Hydro- and Aerodynamics Centre "Acad. Angel Balevski", \\ Bulgarian Academy of Sciences \\ 1, William Froude St., 9003 Varna, Bulgaria, \\ e-mails:r.kishev@bshc.bg; s.kirilova@bshc.bg; o.videnova@bshc.bg
}

\begin{abstract}
This paper presents the methodology and results of an experimental study of two types of ring fish farms cages in different mooring configurations for the study of their interaction with the surface current and waves, including deformations of the elastic frame and the net cage, changes in the local speeds of the water stream inside the net, and the forces in the mooring lines.

Keywords: fish farm, fish cages, fish nets, moored marine structures, model tests in waves.
\end{abstract}

\section{INTRODUCTION}

Floating fish farms are sophisticated engineering facilities operating under severe environment (sea waves, strong wind and currents). Maintaining the technological process places high demands on the structure of the farm cage frame in terms of shape stability, local stresses, deformations, etc., but particular attention is paid to net and anchoring systems behavior.

Increasing capacity and productivity as well as reducing costs of production and operation of fish farms located in a natural habitat pose a number of specific design and operational requirements, among which:

- Provision of necessary volume inside the net for proper growth of the selected fish species (place for normal fish movement, minimal ring deformations and net offsets to avoid injury of fishes);

- Ensuring circulation (inflow) of fresh water rich of oxygen;

- Providing sufficient mechanical strength of the structure (minimum deformations, horizontal and vertical excursions and accelerations) when operating

\footnotetext{
* Corresponding author.

DOI: 10.7546/EngSci.LVIII.21.02.02
} 
in bad environment (strong wind, currents, waves), while keep using simple design solutions and generally available materials to reduce costs and facilitating operation and service;

- Minimizing of tensions in the mooring lines (holding gears or systems);

- Limiting the possibility of fish escape from the closed area;

- Easy access and provision of secure working conditions for the staff in maintenance of facility, feeding, adding necessary medicine treatments, cleaning, monitoring, sampling, etc.

The Bulgarian Ship Hydrodynamics Centre (BSHC) has undertaken a precise and versatile study of different fish farm configurations under the influence

of certain extremal conditions [1-4]. In a previous paper [5], the behaviour of a generic fish farm cage in calm water and surface current has been considered. The present paper continues presentation of this experimental study with the results of investigations on cage interaction with waves, including deformations of the elastic frame and the net, local velocities of the water stream inside the cage, and the forces in the mooring lines.

\section{DESCRIPTION OF GENERIC CAGE CONFIGURATIONS}

Considering the character of marine zones along the Black Sea coast and their openness to the sea, as well as the easiness of service and up-keeping, it was concluded that the single ring type cages will be more effective.

Two net shapes have been compared, as illustrated in Fig. 1 - cone shape and cylindrical shape. For the sake of compatibility, both models had one and the same size. The mooring has been imitated by horizontal rope harness,
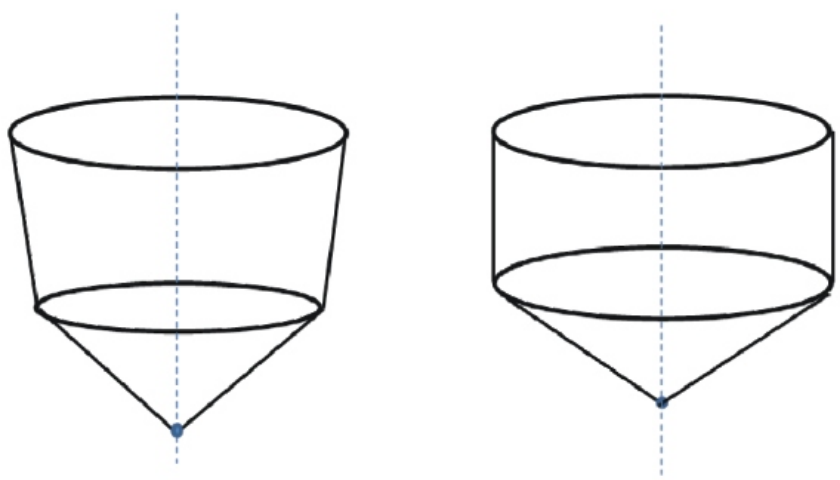

Fig. 1. Sketch of cone and cylindrical shapes tested 
and single hanging or suspended hard heavy rings have been used for deepening and keeping the space inside the cage. The elasticity of the flexible ring floater has been modelled according to the procedure outlined in [2]. The net elements (type and diameter of the rope) have been modeled according to the recommendations in [6] and [7].

\section{EXPERIMENTAL SET-UP}

The model tests have been performed in the BSHC deep water basin $(200 \times$ $16 \times 6.5 \mathrm{~m})$. The cage models in practically assumed model scale have been situated under the main measuring frame of the towing carriage. Reversed motion by towing has been used to model the current flow. The towing straps have been connected to the line force gauges by non-stretchable threads through free rotating pulleys and linear springs with model stiffness imitating prototype mooring system stiffness. The model mooring lines have been pre-tensed correspondingly. At both ends of the ring, light reflection balls have been arranged in order to measure horizontal offsets of the elastic ring form by optical tracing.

\section{TEST PROGRAM}

The two models outlined above, as well as the single floating ring, have been subjected to two series of tests, as follows:

- Towing tests in calm water within the speed range $(0.25 \div 1.25) \mathrm{m} / \mathrm{s}$ full scale to imitate current (results from this series have been outlined in [5]);

- Towing tests in regular waves of length 25, 56 and $100 \mathrm{~m}$ full scale and various wave heights, within the range $(0.25 \div 0.7) \mathrm{m}$ full scale.

\section{BASIC RESULTS AND FINDINGS}

\subsection{Floating ring deformations and offsets}

Under the joint action of waves and current, the moored floating elastic ring shifts in direction of excitation, until reaching a new equilibrium position, at which the wave drift and current force are opposed by mooring force. The wave orbital motion excites oscillations around this new offset.

In Figure 2, sample is shown about mean horizontal offsets fore and aft in wave condition of high frequency of occurrence. Comparing mean offsets in waves and those in still water [5], it could be concluded that wave drift is 

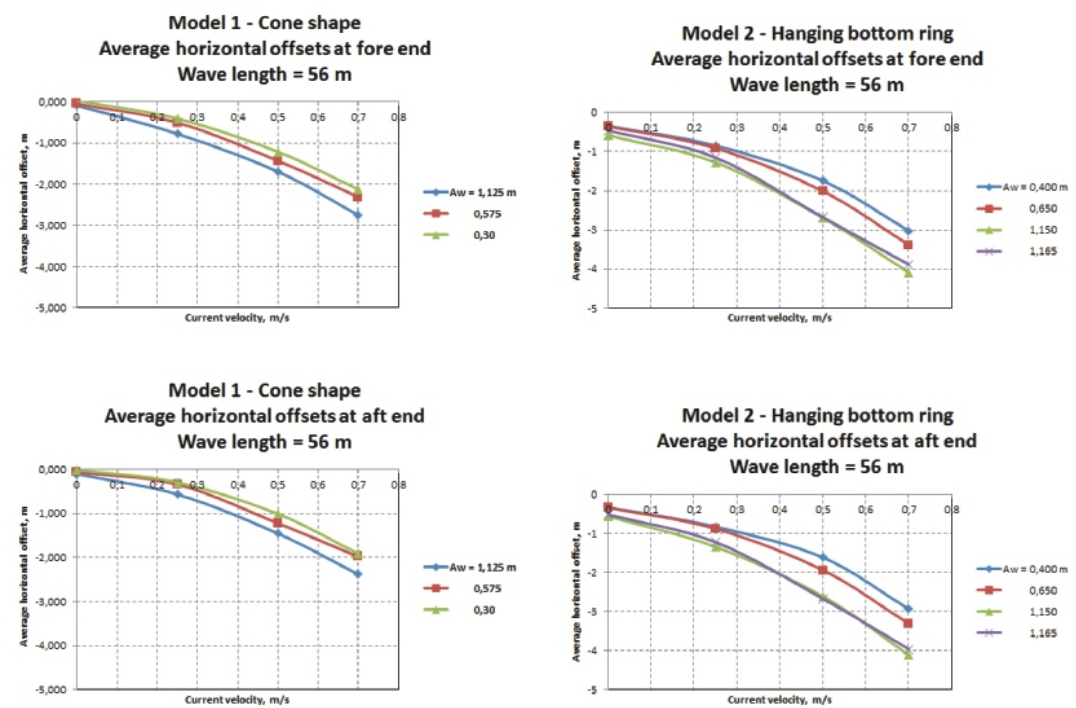

Fig. 2. Average horizontal offsets at the fore and aft ends of the ring floater for a medium sized wave
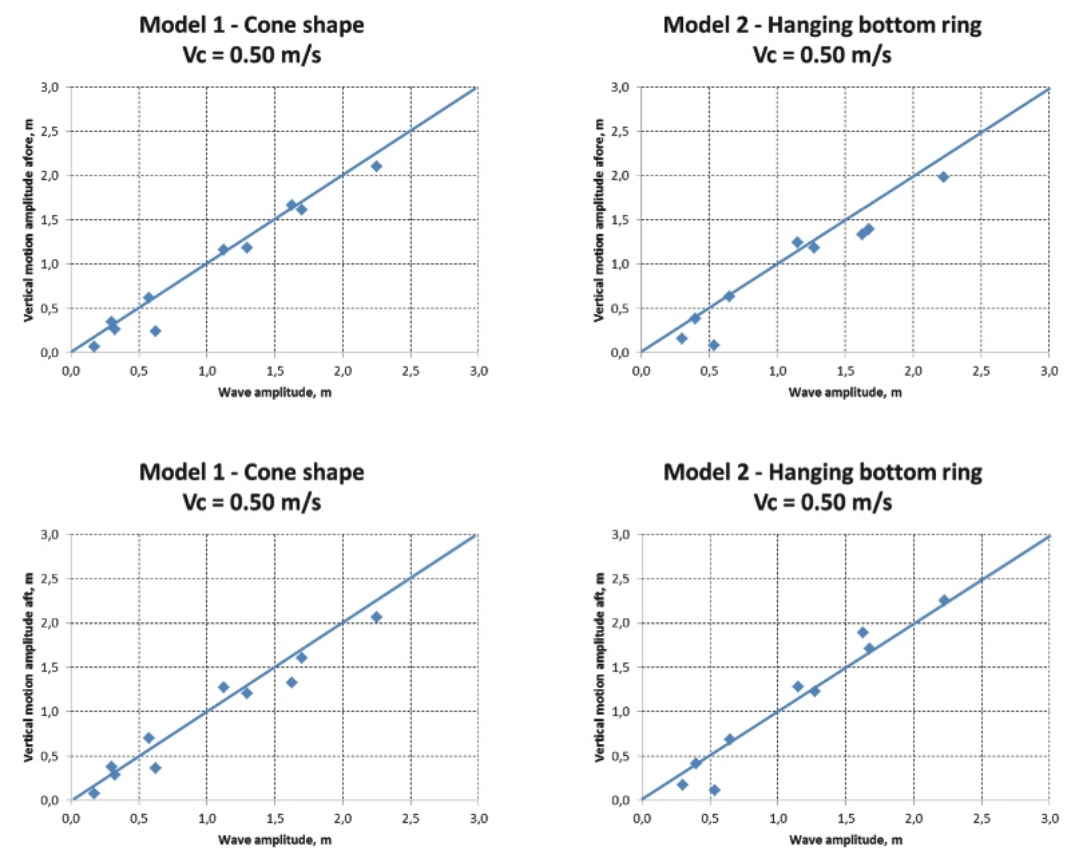

Fig. 3. Vertical amplitudes at the fore and aft ends of the ring floater against wave excitation amplitudes 
minor against the shift due to cage resistance in the current flow. Model 1 (cone shape) shows less horizontal offsets than Model 2 (cylindrical shape) due to the larger mass of the Model 2 cage.

In Figure 3, the relation between vertical motion amplitudes at both ends of the ring floater and the wave circular motion amplitudes is shown for the two models. Waves of several steepness have been tested, but in both cases the elasticity of the ring floater ensures only minor excursions of the ring ends from the free surface. This is important for preventing fish escape from the cage in wave conditions.

\subsection{Tension forces in mooring lines}

Tension forces in mooring lines obviously follow the pattern of horizontal offsets. The average line forces increase in waves with current velocity in the same manner like the case in calm water, but additional wave drift force is added, which depends slightly on wave amplitude, Fig. 4. The oscillatory part, controversially, strongly depends on wave amplitudes but not on cage geometry.
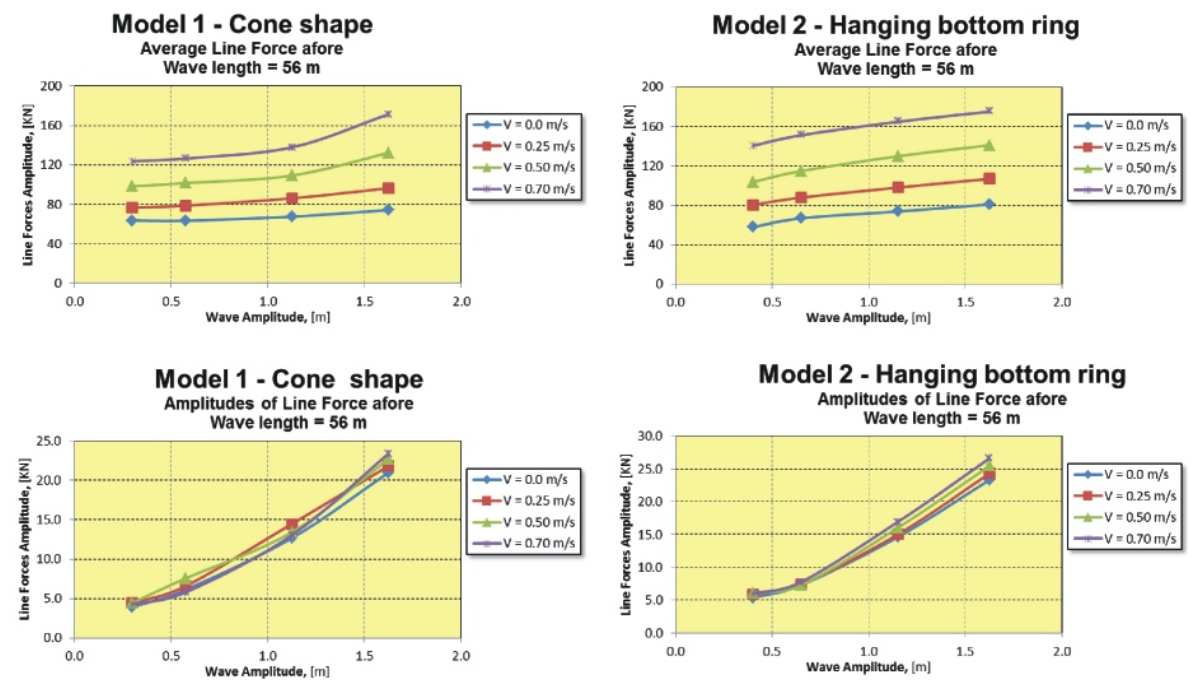

Fig. 4. Average tensions and amplitudes of line forces in front moorings

\subsection{Flow stagnation in waves and current due to cage presence}

The fresh water inflow inside the cage is of great importance to fish breeding as oxygen supplier. The cage net acts as an obstacle and causes flow 
turbulization and corresponding speed reduction. This effect has been studied in still water condition in [5]. In Figure 5, the same effect is traced for wave condition. It can be seen that the wave presence does not significantly influence the flow stagnation, which follows from the fact that wave motion is just orbital motion without mass transport.
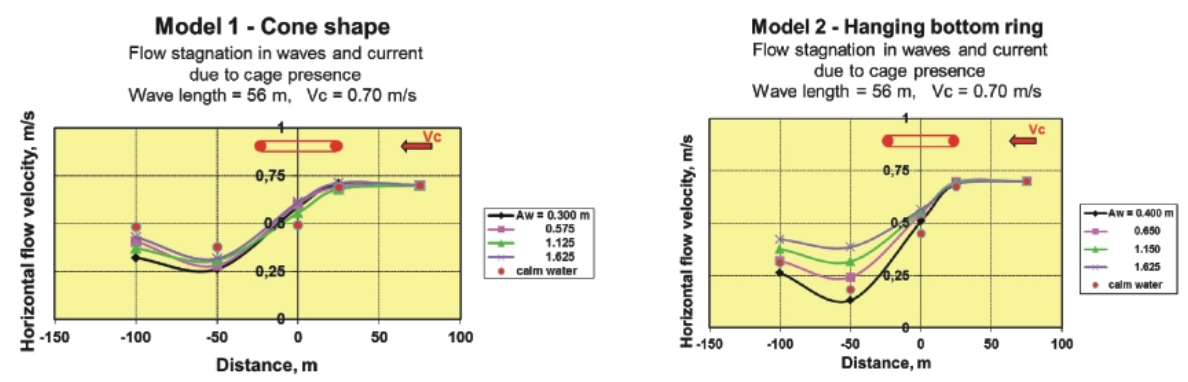

Fig. 5. Flow stagnation inside and behind the cage at combined wave and current excitation

\section{CONCLUSION}

- Both variants of single ring fish farm cages demonstrated good overall behaviour in combined wave/current excitation from the viewpoint of form keeping and permeability. Average mooring line tensions and ring offsets depend mostly on current velocity, and oscillatory values depend on wave parameters. More wide range of wave frequencies and amplitudes should be tested in the future in order to cover entire wave energy spectrum.

- The behaviour of the cage in waves and current depends not only on the geometry and mooring scheme, but also on appliances for deepening and keeping form of the cage, which also lead to mass variations. Various technical decisions are available and must be subjected to additional experiments for their evaluation.

\section{REFERENCES}

[1] R. Kishev, V. Rakitin, Y. Yovev, and R. Nachev, Hydrodynamic Model Tests of Fish Farm Cage System, in: $7^{\text {th }}$ Black Sea International Conference, Varna, 2004.

[2] R. Kishev, V. Rakitin, And Y. Yovev, Model Investigation of Dynamic Behaviour and Wave Loads on a Fish Farm Cage, in: $4^{\text {th }}$ International Conference on Hydroelasticity in Marine Technology, Wuxi, China, 2006. 
[3] R. Kishev, V. Rakitin, S. Kirilova, and O. Videnova, Fish Farm Model Experiments (Part 1), BSHC Internal Report, 2013.

[4] R. Kishev, V. Rakitin, S. Kirilova, and O. Videnova, Fish Farm Model Experiments (Part 2), BSHC Internal Report, 2015.

[5] R. Kishev, V. Rakitin, S. Kirilova, and O. Videnova, Experimental Investigation of Floating Fish Farms Behaviour in Open Sea Environment (Part 1 Calm Water Behaviour), in: ${ }^{\text {st }}$ International Conference of Marine Engineering, NVNA Varna, Bulgaria, 10-11 September, 2018.

[6] A. A. Turner, T. L. Jeans, and G. K. Reid, Experimental Investigation of Fish Farm Hydrodynamic Wake Properties on 1:15 Scale Model Circular Aquaculture Cages - OMAE 2015-42140, St. John's, Newfoundland, Canada, 2015.

[7] B. A. Christensen, Hydrodynamic Modeling of Fishing Nets, in: IEEE OCEAN'75 Conference, San Diego, CA, 1975.

Received April 05, 2021

Engineering Sciences, LVIII, 2021, No. 2 